\title{
Share of current unmet need for modern contraceptive methods attributed to past users of these methods in India
}

\author{
Ankita Shukla $^{1 \star}\left(\mathbb{D}\right.$, Anrudh K. Jain $^{2}\left(\mathbb{D}\right.$, Rajib Acharya ${ }^{1}$, F. Ram ${ }^{3}$, Arupendra Mozumdar ${ }^{1}$ (D), \\ Abhishek Kumar ${ }^{1}$, Subrato Mondal ${ }^{4}$ and Niranjan Saggurti ${ }^{1}$ \\ ${ }^{1}$ Population Council - India Office, New Delhi, India, ${ }^{2}$ Population Council, New York, USA, ${ }^{3}$ International Institute for \\ Population Sciences, Mumbai, India and ${ }^{4}$ USAID/India, American Embassy, Chanakya Puri, New Delhi, India \\ ${ }^{\star}$ Corresponding author. Email: ashukla@popcouncil.org
}

(Received 15 November 2019; revised 22 April 2020; accepted 22 April 2020; first published online 15 June 2020)

\begin{abstract}
Despite persistent efforts, unmet need for contraceptives in India has declined only slightly from $14 \%$ to $13 \%$ between 2005-06 and 2015-16. Many women using a family planning method discontinue it without switching to another method and continue to have unmet need. This study quantified the share of current unmet need for modern contraceptive methods attributed to past users of these methods in India. Data were drawn from two rounds of the National Family Health Survey conducted in 2005-06 and 2015-16. Using information on women with current unmet need, and whether they used any modern method in the past, the share of past users with current unmet need for modern methods was calculated. Bivariate and multivariate analyses were performed. Among 46 million women with unmet need, 11 million were past users of modern methods in 2015-16. The share of current unmet need attributed to past users of modern contraceptive methods declined from $27 \%$ in $2005-06$ to $24 \%$ in $2015-16$. Share of current unmet need attributed to past users was associated with reversible method use. This share rose with increased use of modern reversible methods. With the Indian family planning programme's focus on increasing modern reversible method use, the share of unmet need attributed to past users of modern methods is likely to increase in the future. The programme's emphasis on continuation of contraceptive use, along with bringing in new users, could be one of the key strategies for India to achieve the FP2020 goals.
\end{abstract}

Keywords: Modern contraceptives; Unmet need; Contraceptive discontinuation

\section{Introduction}

At the London Summit on Family Planning held in July 2012, world leaders made commitments to providing access to modern contraceptives to 120 million women and girls with unmet need for family planning by 2020 . India pledged not only to provide family planning services to 48 million additional women by 2020 (i.e. $40 \%$ of the total global commitment of 120 million) but also to sustain the current coverage of over 100 million users (FP2020, 2012; Brown et al., 2014). This commitment to sustaining current users is important as the success of a family planning programme depends as much on continuation of method use by current users as the recruitment of new users (Jejeebhoy, 1991).

The progress of the family planning programme in India was, however, less than expected in the last decade 2005-06 to 2015-16. According to the most recent Demographic and Health Survey (National Family Health Survey 2015-16) there had been slight decline in modern 
contraceptive prevalence (from $48.5 \%$ to $47.7 \%$ ), a very minor increase in the use of modern reversible methods (from $10.2 \%$ to $11.4 \%$ ) and a high proportion of women discontinuing method use for reasons unrelated to their fertility intentions. The contraceptive discontinuation rate (based on episodes of use) for modern spacing methods was 45\% in 2015-16: an increase of 2\% from 2005-06 (IIPS \& Macro International, 2007; IIPS \& ICF, 2017). If this high rate of discontinuation continues, many current users of family planning will join the non-user group and some of them will contribute to the pool of non-users with unmet need for contraception, thereby adding further challenges to achieving FP2020's ambitious goal. Considering the steep FP2020 target committed to by India and a stagnant modern contraceptive prevalence, it is now more important than ever to understand the contribution of users who have discontinued using a modern method (referred to as 'past users' in this paper) to the current level of unmet need for contraception in the country.

Jain and colleagues (2013), in their analysis of 34 Demographic and Health Surveys (DHS), estimated that $38 \%$ of currently married women with unmet need for family planning had used some modern contraceptives in the past. Based on this estimation they concluded that a large section of women - 49 million of the 258 million women who were currently using modern contraception in the 69 poorest countries - would contribute to the pool of non-users with unmet need (Jain et al., 2013) and this would make the global goal of adding 120 million users by 2020 even more challenging.

Studying the contribution of past users to the current level of unmet need for contraception is important from several perspectives. First, addressing the reasons for discontinuation for women who were using a family planning method and discontinued it without switching to another modern method, despite their continued desire to avoid pregnancy, can be an effective programme intervention.

Second, past users who discontinued using a method are considered to be a measure of poor quality of care of family planning services (Jain, 1989; Blanc et al., 1999). Contraceptive discontinuation among women who still want to delay pregnancy may indicate ineffectiveness of the ongoing programmes, as these are the women who once overcame all awareness and accessrelated obstacles and chose to use a modern method but stopped using it after a while. Moreover, it has also been found in panel studies that women's contraceptive needs may change over time (Jain et al., 2014) for valid reasons. Yet, family planning programmes are mostly concerned about awareness and accessibility of contraceptives, and programme strategies seldom consider the requirements of women who start using a method but then discontinue.

Furthermore, exploring reasons for not using contraceptives provides a comprehensive picture of the gaps in efforts and reveals where programmes are failing to meet the family planning needs of women. Not all women discontinue due to reduced need, i.e. a desire to become pregnant, infrequent sex, absence of husband, menopause or sub-fecundity. Previous multi-country research has found that more than half of discontinuations are among women who have method-related problems (Castle \& Askew, 2015). These women may have had inadequate counselling on how to use the method or how to handle side-effects. Incorporating all the above-mentioned concerns will increase the likelihood of a family planning programme's success. To lower overall unmet need, interventions are needed to address family planning service quality, and to reduce premature discontinuation.

Though a few past studies have attempted to assess unmet need and discontinuation rates and their determinants in India, to the authors' knowledge none has attempted to quantify the share of current unmet need attributed to past users. The present study aimed to estimate the share of current unmet need attributed to past users of modern methods, examine the variation in the share by state and selected background characteristics and explore the changes in the patterns of the share of past users to current unmet need between NFHS-3 (2005-06) and NFHS-4 (2015-16). Along with this, the reasons reported by non-users of contraceptives with unmet need were also examined. 


\section{Methods}

\section{Data}

Data for this cross-sectional analysis were drawn from the two rounds of the National Family Health Surveys conducted in 2005-06 (NFHS-3) and 2015-16 (NFHS-4). These surveys provide data on population characteristics, fertility and mortality, contraceptive use, health and nutrition for all the states and union territories of India. In the NFHS-3, 124,385 women of reproductive age (15-49 years) were interviewed from 109,041 households, with a response rate of $95 \%$. In the NFHS-4, 699,686 women aged 15-49 were interviewed from 571,660 households with a response rate of $97 \%$. A detailed description of the sample and study design of the two surveys is available in national reports (IIPS \& Macro International, 2007; IIPS \& ICF, 2017). The present analysis was restricted to currently married women aged 15-49: 93,089 women in NFHS-3 and 511,377 women in NFHS-4.

\section{Past users of modern methods}

Currently married women aged 15-49 were divided into three categories: women who had never used a modern contraceptive method (never user), women who had ever used a modern method in the past but were not using one at the time of the survey (past users) and women who were using a modern method at the time of the survey (current users).

\section{Unmet need for modern contraceptives}

In the NFHS-4, 'unmet need for contraceptives' was defined as women who wanted to space or limit their childbearing but were not using any method at the time of the survey, following the revised definition of unmet need for contraceptives (Bradley et al., 2012). In this study a slightly modified definition was used, and in addition to women with unmet need for any contraceptives, all those who were using a traditional contraceptive method at the time of the survey were also included. This slightly different definition of unmet need aligns with both the FP2020's focus (on modern contraceptive method use only) and that of India's family planning programme. Simply put, the new definition of unmet need was as follows: currently married women who wanted to space or limit their childbearing but who were not using any 'modern' contraceptive method at the time of the survey were defined as 'having unmet need for modern contraceptives'. Women with current unmet need were divided in two groups: those who had never used a modern method prior to the survey (never users with current unmet need) and those who had used a modern method but discontinued its use before the survey (past users with current unmet need). It should be noted that among women who discontinued the use of a modern method (past users) some no longer had any need for contraception (past users with no need); and some past users continued to have an unmet need for contraception at the time of the survey (past users with unmet need). Thus, past users were also divided into two groups: those who continued to have an unmet need and those who did not.

\section{Analytical approach}

The main outcome variable for the analysis was the share of current unmet need contributed by past users of modern contraceptive methods. This outcome variable was estimated by the number of past users of modern methods who had unmet need as a percentage of the total number of women with current unmet need for modern methods (including both past users and never users with unmet need for modern methods). Thus, past users with no further need for modern methods were not included in the numerator of the outcome variable.

Reasons reported by past users of modern contraceptives for not using any method at the time of the survey were also examined. This analysis did not include those who were using traditional methods at the time of survey, as this information was not collected from them. The reasons were 
grouped into six major categories: fertility-related reasons (no sex, infrequent sex, menopausal/ hysterectomy, sub-fecund/infecund and postpartum-amenorrhoea/breastfeeding), opposition to use (woman opposed, partner opposed, others opposed and religious prohibition), lack of awareness of method/source, lack of access (lack of access/too far, and costs too much), health-related reasons (fear of side-effects/health concerns, inconvenient to use and interferes with body) and other reasons (up to God, does not like existing methods and other reasons). Throughout this paper past users of modern methods are termed 'past users' and unmet need for modern methods is termed 'unmet need'. National as well as state-level estimates of selected outcomes were calculated using appropriate sample weights.

All the estimates were calculated using the svyset command in STATA, which specifies the variables that contain information about the survey design, such as the primary sampling unit, analysis weight and stratum. To estimate the magnitude of unmet need and the share of past users in numbers, the number of women with unmet need for modern methods and past users of modern methods with current unmet need in the NFHS-4 were also calculated. For this, the method suggested by Meekers and colleagues was used (Meekers et al., 2016).

A logistic regression analysis, controlling for state effects, was performed to understand predictors of the outcome indicator (being a past user of modern methods and having unmet need at the time of the survey). The regression was controlled for age (15-24, 25-34, 35-49 years); number of children $(0-1,2,3+)$; education (no education, $1-5$ years, $5-10$ years and more than 10 years); place of residence (urban, rural); caste (scheduled tribe/scheduled caste (SC/ST), other backward caste (OBC) and other); religion (Hindu, Muslim and other); household wealth index (a composite score given in the NFHS based on household assets categorized into five categories: poorest, poorer, middle, richer and richest). States with values closest to the national value of the outcome variable were taken as the reference category, i.e. Tamil Nadu in NFHS-3 and Gujarat in NFHS-4.

The adjusted percentage of the share of past users with unmet need was estimated by using the probability predicted from the logistic regression models. To test the significance of the change in the outcome variable over time, significance levels of change at $95 \%$ confidence level were calculated from differences in the confidence interval between the two survey points (Altman \& Bland, 2011).

The unit of analysis was 'currently married women' and values were considered significant at $p<0.05$. All analyses were done in STATA 14 using sample weights.

\section{Results}

\section{National level}

About $47.8 \%$ of currently married women (511,377 respondents) were using a modern method in 2015-16 - a decline from 48.5\% in 2005-06 (Table 1). However, use of reversible modern methods increased from $10.2 \%$ in $2005-06$ to $11.5 \%$ in $2015-16$. In $2005-06,9.0 \%$ were past users and $15.8 \%$ were never users of modern methods. In 2015-16, the proportion of past users declined to $8.0 \%$ and never users to $14.2 \%$. During this period, unmet need for modern methods declined from $21.7 \%$ to $18.6 \%$. At the national level, past users accounted for about $24 \%$ of women with unmet need for modern methods at the time of the NFHS-4 survey and the remaining $76 \%$ of unmet need was accounted for by never users. The share of past users to unmet need for modern methods declined from $27 \%$ in $2005-06$ to $24 \%$ in $2015-16$. The regression model controlled for independent variables and showed that the decline was statistically significant.

\section{Background characteristics}

The relationship between the share of past users with unmet need and background characteristics was similar in both time periods. The adjusted share of past users with unmet need increased with women's age, parity, education and household wealth (Table 2). It was higher in urban areas than 
Table 1. Descriptive summary of the indicators of family planning, past users of modern methods and unmet need for modern methods, NFHS-3 and NFHS-4

\begin{tabular}{|c|c|c|c|c|}
\hline & \multicolumn{2}{|c|}{ NFHS-3 } & \multicolumn{2}{|c|}{ NFHS-4 } \\
\hline & $\%$ & $95 \% \mathrm{Cl}$ & $\%$ & $95 \% \mathrm{Cl}$ \\
\hline Number of currently married women & \multicolumn{2}{|c|}{93,089} & \multicolumn{2}{|c|}{511,377} \\
\hline Unmet need for modern methods & 21.71 & $21.07,22.37$ & 18.64 & $18.41,18.87$ \\
\hline Current users of modern methods & 48.50 & $47.60,49.47$ & 47.76 & $47.38,48.14$ \\
\hline Permanent method use & 38.34 & $37.38,39.30$ & 36.26 & $35.87,36.66$ \\
\hline Reversible method use & 10.20 & $9.73,10.68$ & 11.50 & $11.24,11.75$ \\
\hline Traditional method use & 7.80 & $7.36,8.26$ & 5.78 & $5.61,5.96$ \\
\hline Past users of modern methods & 9.03 & $8.66,9.42$ & 8.02 & $7.85,8.19$ \\
\hline With unmet need & 5.87 & $5.59,6.16$ & 4.46 & $4.35,4.58$ \\
\hline With no unmet need & 3.17 & $3.00,3.34$ & 3.55 & $3.46,3.65$ \\
\hline Never users with unmet need & 15.84 & $15.31,16.39$ & 14.18 & $13.99,14.37$ \\
\hline $\begin{array}{l}\text { Past users of modern methods as percentage of those } \\
\text { with unmet need }\end{array}$ & 27.03 & $25.95,28.15$ & 23.95 & $23.44,24.48$ \\
\hline $\begin{array}{l}\text { Never users of modern methods as percentage of those } \\
\text { with unmet need }\end{array}$ & 72.97 & $71.85,74.05$ & 76.05 & $75.52,76.56$ \\
\hline
\end{tabular}

${ }^{a}$ Change in proportion over time was significant when all other predictors were controlled.

in rural areas. The adjusted odds ratios (AORs) of the share of past users with current unmet need increased with age (NFHS-4: 1.6 and 2.9, respectively for ages 25-34 and 35-49) and parity (NFHS-4: 1.8 and 1.9, respectively, for women with 2 and 3 or more children, respectively). Women with education had higher odds of being past users with unmet need in comparison to women with no education. Finally, AORs of the contribution of past users to unmet need for modern contraception increased with increasing wealth (NFHS-4: 1.6 to 2.6, respectively, in the 2nd quintile to 5 th quintile). Education and wealth differentials decreased over time, but rural-urban differences increased slightly. There was no effect of caste or religion on the odds of share of past users with unmet need. The adjusted share of past users to unmet need decreased in almost every stratum, except among women aged 35-49 years. The share of past users showed an increase among women of 35-49 years of age. The decline over time was not significant among women with no children, with no education and in the poorest two groups.

\section{State-level variations}

The share of past users with unmet need in a state was highly correlated with the use of modern reversible methods in the state (NFHS-3 $r=0.43, p<0.05$, and NFHS- $r=0.50, p<0.05$ ). The results of a multiple regression analysis indicated that the regression coefficients of use of a modern reversible method were positive and significant (data not shown).

The share of past users with unmet need was highest in Punjab (58\%), followed by Sikkim (48\%), Uttarakhand (40\%), Himachal Pradesh (40\%) and West Bengal (39\%) in 2015-16 and was comparatively low in the southern states (10-18\%), with the exception of Kerala (32\%) (Fig. 1). Between NFHS-3 and NFHS-4, twelve states had a decline in the share by more than 5 percentage points, and Tripura, Manipur, Delhi and Jharkhand were the states with the highest declines. On the other hand, seven states showed an increase of more than 5 percentage points in 
Table 2. Adjusted odds ratios (AOR) and adjusted proportions of share of current unmet need attributed to past users, NFHS-3 and NFHS-4

\begin{tabular}{|c|c|c|c|c|c|}
\hline & \multicolumn{2}{|c|}{ AOR } & \multicolumn{2}{|c|}{ Adjusted proportion } & \multirow[b]{2}{*}{ Change } \\
\hline & NFHS-3 & NFHS-4 & NFHS-3 & NFHS-4 & \\
\hline \multicolumn{6}{|c|}{ Age of women (years) } \\
\hline $15-24$ & 1.00 & 1.00 & 20.26 & 15.64 & $-4.61^{*}$ \\
\hline $25-34$ & $1.56^{\star}$ & $1.62^{\star}$ & 27.44 & 22.46 & $-4.98^{\star}$ \\
\hline $35-49$ & $1.83^{*}$ & $2.88^{\star}$ & 30.41 & 32.84 & $2.42^{\star}$ \\
\hline \multicolumn{6}{|l|}{ No. children } \\
\hline $0-1$ & 1.00 & 1.00 & 18.03 & 17.65 & -0.39 \\
\hline 2 & $2.03^{*}$ & $1.79^{\star}$ & 29.21 & 26.48 & $-2.73^{*}$ \\
\hline $3+$ & $2.24^{\star}$ & $1.87^{\star}$ & 31.02 & 27.26 & $-3.76^{\star}$ \\
\hline \multicolumn{6}{|l|}{ Education (years) } \\
\hline No education & 1.00 & 1.00 & 19.73 & 19.22 & -0.51 \\
\hline $1-5$ & $1.75^{\star}$ & $1.46^{\star}$ & 28.97 & 25.00 & $-3.97^{\star}$ \\
\hline $5-10$ & $2.15^{\star}$ & $1.51^{\star}$ & 32.90 & 25.51 & $-7.40^{\star}$ \\
\hline $10+$ & $2.28^{\star}$ & $1.50^{\star}$ & 34.10 & 25.43 & $-8.67^{\star}$ \\
\hline \multicolumn{6}{|c|}{ Place of residence } \\
\hline Rural & 1.00 & 1.00 & 26.28 & 23.24 & $-3.03^{*}$ \\
\hline Urban & 1.06 & $1.08^{\star}$ & 27.22 & 24.43 & $-2.79^{\star}$ \\
\hline \multicolumn{6}{|l|}{ Caste } \\
\hline $\mathrm{SC} / \mathrm{ST}$ & 1.00 & 1.00 & 26.70 & 23.28 & $-3.42^{*}$ \\
\hline $\mathrm{OBC}$ & 0.93 & 1.01 & 25.49 & 23.41 & $-2.08^{\star}$ \\
\hline Other & 1.05 & 1.08 & 27.61 & 24.44 & $-3.17^{*}$ \\
\hline \multicolumn{6}{|l|}{ Religion } \\
\hline Hindu & 1.00 & 1.00 & 26.14 & 23.72 & $-2.43^{*}$ \\
\hline Muslim & 1.14 & 0.98 & 28.40 & 23.36 & $-5.04^{*}$ \\
\hline Other & 1.1 & 1.03 & 27.83 & 24.11 & $-3.72^{\star}$ \\
\hline \multicolumn{6}{|c|}{ Household wealth } \\
\hline 1st quintile & 1.00 & 1.00 & 15.09 & 15.66 & 0.57 \\
\hline 2nd quintile & $1.63^{\star}$ & $1.56^{\star}$ & 21.91 & 21.74 & -0.17 \\
\hline 3rd quintile & $2.24^{\star}$ & $1.76^{\star}$ & 27.40 & 23.68 & $-3.72^{\star}$ \\
\hline 4th quintile & $2.76^{\star}$ & $2.10^{*}$ & 31.35 & 26.70 & $-4.65^{\star}$ \\
\hline 5th quintile & $3.93^{\star}$ & $2.55^{\star}$ & 38.70 & 30.20 & $-8.50^{*}$ \\
\hline
\end{tabular}

${ }^{*} p<0.05$; significance level of change is estimated using differences in $\mathrm{Cl}$ of odds ratios between the two surveys. The adjusted values are adjusted for all the predictors mentioned in the above table along with states. The first categories of the predictors are considered to be the reference category.

the share - Punjab (24), Himachal Pradesh (11), Mizoram (11), Uttarakhand (9), Meghalaya (9), Haryana (8) and Maharashtra (7). Overall, in 2015-16, there were 10.9 million past users in the country, of whom 50\% came from four states: Uttar Pradesh (2.32 million), West Bengal (1.77 million), Maharashtra (0.82 million) and Odisha (0.72 million). 


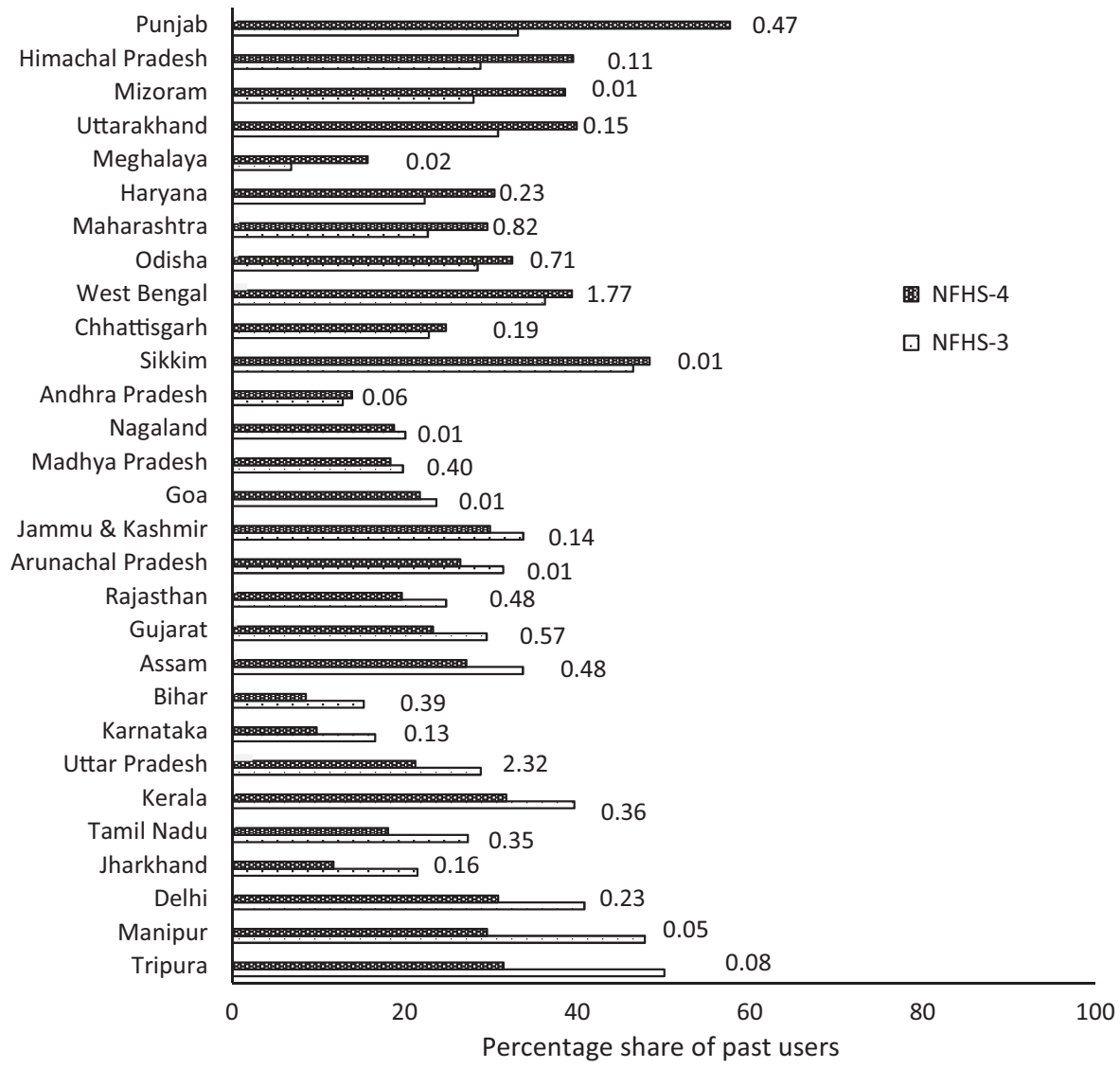

Figure 1. Distribution of share of unmet need for modern methods attributed to past users by Indian states, NFHS-3 and NFHS-4. The numbers represent the number of past users with unmet need in millions and the bars represent the percentage share of past users in current unmet need in NFHS-3 and NFHS-4.

The adjusted odds ratios and adjusted proportion (Table 3) showed that the increase in share over time was significant in Punjab, Himachal Pradesh, Mizoram, Meghalaya, Haryana, Maharashtra, Uttarakhand and a few other states.

\section{Reasons for not using contraceptives among past users of modern methods}

Among past users who had unmet need for modern contraception, a high proportion reported fertility-related reasons (Fig. 2). Between NFHS-3 and NFHS-4, reporting of fertility-related reasons declined from $55 \%$ to $52 \%$ and health-related reasons from $15 \%$ to $12 \%$. However, opposition-related reasons increased from $13 \%$ in NFHS-3 to $22 \%$ in NFHS- 4 .

\section{Discussion}

With the backdrop of India's global commitment to adding 120 million users of modern contraceptive methods by 2020 , and slow progress in family planning use in the last decade, it becomes important to explore alternative strategies that the country's family planning programme can adopt to achieve this ambitious target. This study examined the group of women with unmet need for modern contraceptives who had used a modern method but discontinued using it for 
Table 3. Adjusted odds ratios (AOR) and adjusted proportions of share of current unmet need attributed to past users, by state, NFHS-3 and NFHS-4

\begin{tabular}{|c|c|c|c|c|c|}
\hline & \multicolumn{2}{|c|}{ AOR } & \multicolumn{2}{|c|}{ Adjusted proportion } & \multirow[b]{2}{*}{ Change } \\
\hline & NFHS-3 & NFHS-4 & NFHS-3 & NFHS-4 & \\
\hline Karnataka & $0.58^{*}$ & $0.38^{*}$ & 16.15 & 9.79 & $-6.36^{\star}$ \\
\hline Bihar & 0.77 & $0.51^{\star}$ & 20.02 & 12.57 & $-7.46^{\star}$ \\
\hline Meghalaya & $0.18^{\star}$ & $0.52^{*}$ & 5.93 & 12.94 & $7.00^{\star}$ \\
\hline Andhra Pradesh & $0.51^{\star}$ & $0.62^{\star}$ & 14.65 & 14.75 & 0.094 \\
\hline Jharkhand & 1.36 & $0.64^{\star}$ & 29.15 & 15.26 & $-13.89^{\star}$ \\
\hline Nagaland & $0.51^{\star}$ & $0.64^{\star}$ & 14.63 & 15.27 & 0.64 \\
\hline Goa & $0.46^{\star}$ & 0.65 & 13.58 & 15.37 & 1.79 \\
\hline Tamil Nadu & 1 & $0.76^{\star}$ & 23.91 & 17.42 & $-6.49^{\star}$ \\
\hline Madhya Pradesh & 0.94 & 0.93 & 22.93 & 20.27 & -2.66 \\
\hline Rajasthan & 1.31 & 0.99 & 28.53 & 21.18 & $-7.35^{\star}$ \\
\hline Uttar Pradesh & $1.55^{\star}$ & 0.99 & 31.59 & 21.23 & $-10.36^{\star}$ \\
\hline Gujarat & 0.95 & 1 & 23.08 & 21.42 & $-1.66^{\star}$ \\
\hline Delhi & 1.02 & 1.08 & 24.22 & 22.67 & -1.55 \\
\hline Manipur & $1.83^{*}$ & 1.15 & 34.79 & 23.73 & $-11.06^{*}$ \\
\hline Jammu \& Kashmir & 0.82 & 1.22 & 20.93 & 24.64 & $3.71^{*}$ \\
\hline Kerala & 1.05 & $1.24^{\star}$ & 24.78 & 24.92 & 0.14 \\
\hline Arunachal Pradesh & 1.5 & $1.36^{\star}$ & 30.99 & 26.59 & $-4.40^{\star}$ \\
\hline Chhattisgarh & 1.33 & $1.38^{\star}$ & 28.75 & 26.85 & -1.9 \\
\hline Haryana & $0.61^{\star}$ & $1.41^{\star}$ & 16.87 & 27.19 & $10.32^{\star}$ \\
\hline Assam & 1.29 & $1.42^{\star}$ & 28.24 & 27.39 & -0.85 \\
\hline Maharashtra & $0.66^{\star}$ & $1.42^{\star}$ & 17.90 & 27.33 & $9.43^{*}$ \\
\hline Tripura & $3.15^{\star}$ & $1.50^{\star}$ & 45.92 & 28.39 & $-17.53^{\star}$ \\
\hline Mizoram & 0.81 & $1.61^{\star}$ & 20.72 & 29.71 & $8.99^{\star}$ \\
\hline Himachal Pradesh & 0.77 & $1.82^{\star}$ & 19.86 & 32.11 & $12.24^{\star}$ \\
\hline Odisha & $1.49^{\star}$ & $1.93^{\star}$ & 30.79 & 33.30 & 2.51 \\
\hline Uttarakhand & 0.97 & $2.05^{\star}$ & 23.36 & 34.51 & $11.15^{\star}$ \\
\hline West Bengal & $1.75^{\star}$ & $2.82^{\star}$ & 33.89 & 41.30 & $7.41^{\star}$ \\
\hline Sikkim & $2.19^{\star}$ & $3.05^{\star}$ & 38.35 & 43.05 & $4.69^{\star}$ \\
\hline Punjab & 0.83 & $3.41^{\star}$ & 20.96 & 45.52 & $24.56^{\star}$ \\
\hline
\end{tabular}

${ }^{*} p<0.05$; significance level of change is estimated using differences in $\mathrm{Cl}$ of odds ratios between the two surveys. The adjusted values are adjusted for all the predictors mentioned in Table 2. States with values closer to the national value of the outcome variable were considered to be the reference category, i.e. Tamil Nadu in NFHS-3 and Gujarat in NFHS-4.

some reason (termed 'past users'). They perhaps did not have adequate information or knowledge about methods other than the one they had been using, and discontinued use rather than switch to another method. This type of information could be provided at the initiation (or) at the source of supply, and also during various contacts between women and family planning providers. 


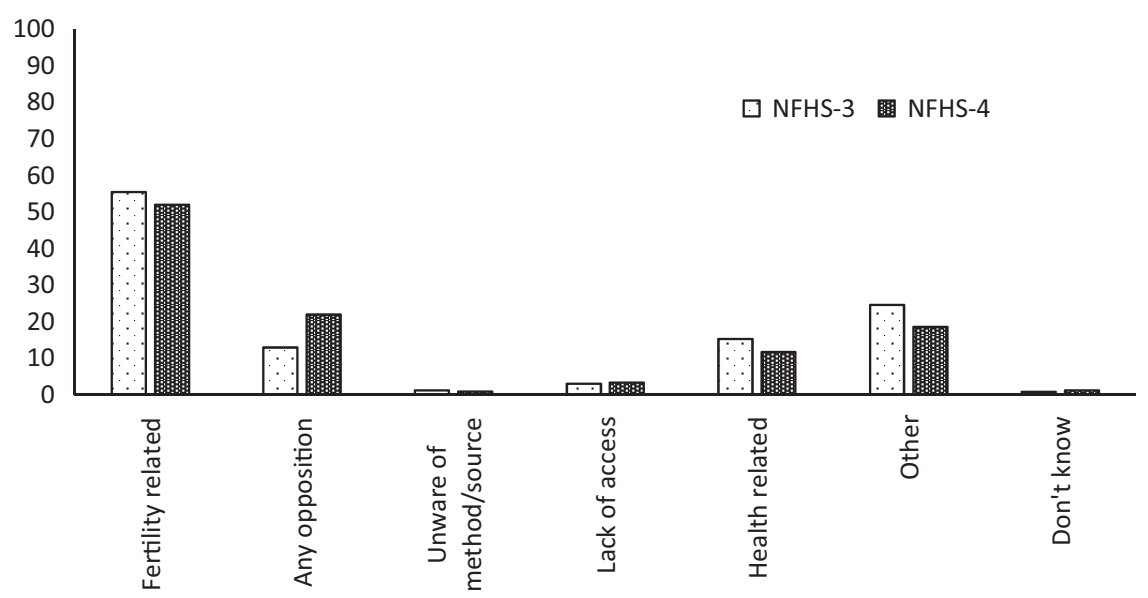

Figure 2. Reported reasons for non-use of contraceptives by past users of modern methods with unmet need, NFHS-3 and NFHS-4.

Three major points emerge from the study findings. First, the number of 'past users of modern methods' in 2015-16 was quite large at 11 million, or $24 \%$ of the 46 million women with unmet need - a modest decline from $27 \%$ in 2005-06. This modest decline of 3 percentage points reflects the net effect of two opposite forces: a reduction in the share of past users due to an increase in quality of care and an increase in the share of past users due to an increase in the use of reversible methods. It appears to be low only in comparison to a substantial increase in quality of care in family planning (the Method Information Index increased from about 15\% in 2005-06 to 32\% in 2015-16), although the recent estimate is not at optimal level (Rana \& Jain, 2020). However, the share of past users between the two surveys would have increased because the use of reversible methods increased between the two surveys. As expected, the share of past users among women with unmet need increased with increasing use of reversible methods. This may be a result of the fact that among modern reversible methods, India's method mix is dominated by condom and pill use, at $6 \%$ and $4 \%$ respectively (IIPS \& ICF, 2017) - methods that are more prone to being discontinued by women compared with long-term methods such as the IUD (Curtis \& Blanc, 1997; Ali \& Cleland, 1999). Hence, states like Punjab, Sikkim and West Bengal, with high modern reversible method use, contributed significantly to the national number of past users. While the majority of condom and pill users sourced the method from the private sector and other sources such as pharmacies, shops, $d a i$ and relatives ( $86 \%$ for condom users and $80 \%$ for pill users), the available evidence suggests no significant difference in the levels of Method Information Index between those accessing methods from public versus private sources (Rana \& Jain, 2020). A small percentage of past users who were not using contraceptive methods currently reported lack of access to a method (3\%) as the reason.

Second, contributions of past users were largely among women from such socio-demographic groups where current use of reversible modern contraception was higher, except for older women and women with parity 3 or above. The relationship was particularly notable by education, urban/ rural residence, caste and household wealth. In the case of older women (aged 35-39 years) or women with three or more children, contributions of past users were higher, possibly because these women had a longer exposure time for using or 'trying' different methods in their reproductive life compared with their younger or lower-parity counterparts.

Third, the analysis found that a high proportion of past users with unmet need reported fertility-related reasons such as no sex, infrequent sex, menopausal/hysterectomy and subfecund/infecund. This is consistent with previous findings in many countries in which a very high 
percentage of women with unmet need cited fertility-related reasons for non-use, i.e. infrequent or no sex (Sedgh \& Hussain, 2014). Data from NFHS-3 and -4 also show that high percentage of nonusers, as well as those women with unmet need, gave fertility-related reasons for non-use (Dhillon et al., 2020). These women perhaps considered themselves at low risk of unintended pregnancy and hence were not willing to use contraception to avoid an unintended pregnancy. However, they were considered as having unmet need for contraception in the DHS. It is possible that these women had a recent pregnancy despite low perceived risk or the unmet need derived measure overestimates the real need for contraception. There appears to be some inconsistency between women's self-perceived risk of pregnancy and the algorithm used to estimate unmet need in the DHS. The resolution of these inconsistencies require further research.

Furthermore, around $22 \%$ of past users reported 'opposition by respondent or others' and $12 \%$ reported 'health concerns' as reasons for not using contraceptives in 2015-16. Side-effects and concerns about health risks have been found to be the most cited reasons for discontinuing contraception in other contexts too (Janowitz et al., 1986; Khan, 2001; Savabi-Esfahany et al., 2006). Had these women had more information or better counselling on side-effects, they may have been in a better position to continue using the method or switch to another method. As other authors have argued, the high discontinuation rate itself is not a big problem as long as women who still want to delay or limit childbearing are able to switch to an alternative method (Barden-O'Fallon et al., 2011). Past literature has documented that adequate counselling and knowledge about sideeffects significantly decrease the chances of contraceptive discontinuation (Cotten et al., 1992; Mtawali et al., 1994; Lei et al., 1996). A positive relationship between quality of care and continuation rates have recently been established through a longitudinal study in India (Jain et al., 2019).

These findings lead to some recommendations for policies and programmes. The contribution of past users was found to be closely related to the number of users of modern reversible methods, and since there has been a secular increase in the use of modern reversible methods in India, the number of past users will increase sharply in the future if adequate measures are not undertaken. This is true for states like Punjab, Sikkim, Uttarakhand and West Bengal, where reversible method use is high. There need to be strategies to reduce discontinuation of methods for reasons such as 'did not like existing methods', 'costs of the method', 'opposition to use family planning' and 'health concerns'. State-specific approaches will also be helpful to curb unmet need. For example, while in Punjab the most-reported reasons were fertility-related or opposition by family, $7 \%$ of past users with unmet need in West Bengal said that they did not like the existing methods, and in Uttarakhand $12 \%$ reported health-related concerns.

Since data on reasons for non-use were only collected from women who were not using any method at the time of the survey, no information was available on why many women choose to use traditional methods over modern methods. Further qualitative research is needed to understand this. The survey questions could be modified, or additional questions framed, to inquire about reasons by type of woman, i.e. reason for never using any modern method, reason for using modern method in the past but not currently and reason for not using any method. Such information would be helpful for the programme to address women's specific needs.

A holistic approach needs to be taken to focus on gatekeepers too; for example, field-level workers should engage women's husbands in discussions on family planning. Given that improving quality of care of family planning services reduces method discontinuation, programmes need to focus on providing women with quality services, particularly giving them information on possible side-effects, managing side-effects and alternative choices of methods. Provision of this information is important for all women irrespective of whether they receive their method from the public or private sector. This could be done whenever a woman comes into contact with the health sector for reproductive health services. The provision of accurate information about various methods and their side-effects has the potential to effectively reduce discontinuation of a method as well as encourage switching to another modern method whenever the original method ceases to suit a woman's needs and circumstances. 
Overall, it is concluded that the Indian family planning programme needs to focus beyond attaining a higher level of contraception use by women/couples. A family planning worker's/provider's duty should not end at recruiting new users into the programme, but should also include the follow-up of existing clients to meet their changing needs.

Funding. This paper was prepared as part of the RASTA initiative of the Evidence Project of the Population Council. The Evidence Project is made possible by the generous support of the American people through the United States Agency for International Development (USAID) under the terms of cooperative agreement No. AID-OAA-A-13-00087. The content of this manuscript is the sole responsibility of the authors and does not necessarily reflect the views of USAID or the United States Government.

Conflicts of Interest. The authors have no conflict of interest to declare.

Ethical Approval. This analysis was based on the Demographic and Health Survey data from India available in the public domain. The data can be downloaded from www.DHSprogram.com. The study conducted a secondary analysis with no identifiable information on survey respondents.

\section{References}

Ali M and Cleland J (1999) Determinants of contraceptive discontinuation in six developing countries. Journal of Biosocial Science 31(3), 343-360.

Altman DG and Bland JM (2011) How to obtain the $P$ value from a confidence interval. BMJ 343, d2304.

Barden-O'Fallon J, Speizer I, Cálix J and Rodriguez F (2011) An analysis of contraceptive discontinuation among female, reversible method users in urban Honduras. Studies in Family Planning 42(1), 11-20.

Blanc A, Curtis S and Croft T (1999) Does contraceptive discontinuation matter? Quality of care and fertility consequences. MEASURE Evaluation Technical Report Series, No. 3.

Bradley S E, Croft TN, Fishel JD and Westoff CF (2012) Revising unmet need for family planning. DHS Analytical Studies No. 25. ICF International Calverton, MD,

Brown W, Druce N, Bunting J, Radloff S, Koroma D, Gupta S et al. (2014) Developing the 120 by 20 goal for the global FP2020 initiative. Studies in Family Planning 45(1), 73-84.

Castle S and Askew I (2015) Contraceptive Discontinuation: Reasons, Challenges, and Solutions. Family Planning 2020, Population Council, New York.

Cotten N, Stanback J, Maidouka H, Taylor-Thomas J and Turk T (1992) Early discontinuation of contraceptive use in Niger and the Gambia. International Family Planning Perspectives 18(4), 145-149.

Curtis K and Blanc A (1997) Determinants of contraceptive failure, switching, and discontinuation: an analysis of DHS contraceptive histories. DHS Analytic Report No. 6. Macro International Inc., Calverton, MD.

Dhillon P, Singh G, Ram F and Saggurti N (2020) Increasing role of abstinence and infecundity in the non-use of contraceptive methods in India. Journal of Biosocial, doi: https://doi.org/10.1017/S0021932020000115.

FP2020 (2012) London Summit on Family Planning. Technical note: data sources and methodology for developing the 2012 baseline, 2020 objectives, impacts and costings. URL: https://www.familyplanning2020.org/sites/default/files/2013_0104_FP_Summit_technical_note_15_June.pdf

IIPS and Macro International (2007) National Family Health Survey 3, 2005-06. International Institute for Population Sciences and Macro International, Mumbai, India.

IIPS and ICF (2017) National Family Health Survey 4, 2015-16. International Institute for Population Sciences, Mumbai, India.

Jain A, Aruldas K, Mozumdar A, Tobey E and Acharya R (2019) Validation of two quality of care measures: results from a longitudinal study of reversible contraceptive users in India. Studies in Family Planning 50(2), 179-193.

Jain AK (1989) Fertility reduction and the quality of family planning services. Studies in Family Planning 20(1), 1-16.

Jain AK, Mahmood A, Sathar Z and Masood I (2014) Reducing unmet need and unwanted childbearing: evidence from a panel survey in Pakistan. Studies in Family Planning 45(2), 277-299.

Jain AK, Obare F, Ramarao S and Askew I (2013) Reducing unmet need by supporting women with met need. International Perspectives on Sexual and Reproductive Health 39(3), 133-141.

Janowitz B, Kane T, Arruda J, Covington D and Morris L (1986) Side effects and discontinuation of oral contraceptive use in southern Brazil. Journal of Biosocial Science 18(3), 261-271.

Jejeebhoy S (1991) Measuring contraceptive use-failure and continuation: an overview of new approaches. Measuring the Dynamics of Contraceptive Use. ST/ESA/SER.R/106. United Nations, New York, pp. 21-51.

Khan M (2001) Side effects and oral contraceptive discontinuation in rural Bangladesh. Contraception 64(3), $161-167$. 
Lei Z, Wu S, Garceau R, Jiang S, Yang Q, Wang W and Vander Meulen T (1996) Effect of pretreatment counseling on discontinuation rates in Chinese women given depo-medroxyprogesterone acetate for contraception. Contraception 53(6), 357-361.

Meekers D, Haynes S and Kampa K (2016) Handbook for Research on the Family Planning Market. Volume 2: Tools and Resources for an In-depth Analysis of the Family Planning Market. Carolina Population Center, University of North Carolina at Chapel Hill, NC.

Mtawali G, Curtis K, Angle M and Pina M (1994) Contraceptive side effects: responding to clients' concerns. OUTLOOK 12(3), X-X.

Rana J and Jain AK (2020) Do Indian women receive adequate information about contraception? Journal of Biomedical Science 52(3), 338-352.

Savabi-Esfahan M, Fadaei S and Yousefy A (2006) Use of combined oral contraceptives: retrospective study in Isfahan, Islamic Republic of Iran. East Mediterranean Health Journal 12(3-4), 417-422.

Sedgh G and Hussain R (2014) Reasons for contraceptive nonuse among women having unmet need for contraception in developing countries. Studies in Family Planning 45(2), 151-169.

Cite this article: Shukla A, Jain AK, Acharya R, Ram F, Mozumdar A, Kumar A, Mondal S, and Saggurti N (2021). Share of current unmet need for modern contraceptive methods attributed to past users of these methods in India. Journal of Biosocial Science 53, 407-418. https://doi.org/10.1017/S0021932020000279 